\title{
Ursodeoxycholic acid augmentation in treatment-refractory schizophrenia: a case report
}

\author{
Mohsen Khosravi[
}

\begin{abstract}
Background: Treatment-resistance is recognized as a significant dilemma in schizophrenia, which has been reported to involve approximately one-third of patients with schizophrenia.

Case presentation: This case report described a 12-week treatment course for a 39-year-old Persian man with treatment-refractory schizophrenia, who showed a significant improvement in terms of positive, negative, and cognitive symptoms after taking ursodeoxycholic acid $300 \mathrm{mg}$ capsules twice a day. Also, ursodeoxycholic acid was well tolerated, and he did not exhibit any side effects during treatment, based on interview and physical examination.

Conclusion: Ursodeoxycholic acid augmentation seems to be an effective treatment strategy for patients with treatment-refractory schizophrenia. However, further investigations in this field need to be carried out through randomized controlled trials.
\end{abstract}

Keywords: Schizophrenia, Therapeutics, Ursodeoxycholic acid, Report

\section{Background}

Treatment-resistance is a significant dilemma in schizophrenia, which has involved many patients, their families, and health care professionals. Treatment-refractory schizophrenia (TRS) is defined as a treatment failure despite the use of two adequate treatment trials with antipsychotics of two different classes (including a 4-to6-week trial of 400 to $600 \mathrm{mg} /$ day chlorpromazine or its equivalent). TRS affects approximately one-third of patients with schizophrenia [1]. Over the past decade, many clinical practice guidelines have recommended clozapine for patients with TRS; however, only $40 \%$ of the patients have met the response criteria [2]. Furthermore, there has been no convincing evidence for the augmentation of clozapine yet; Even "novel" therapies, including N-methyl-D-aspartate receptor (NMDAR)

\footnotetext{
Correspondence: dr_khosravi2016@yahoo.com

Department of Psychiatry and Clinical Psychology, Zahedan University of Medical Sciences, Zahedan 9813913777, Iran
}

enhancers (such as glycine, D-serine, D-cycloserine, and $\mathrm{N}$-methylglycine), yielded contradictory results in clinical trials [3].

Bile acids are known as an associated category of molecules extracted from cholesterol and have been used as therapeutic agents in medicine for a long time [4]. Recent studies have shown that ursodeoxycholic acid (UDCA) and its main conjugate, that is, glycoursodeoxycholic acid (GUDCA), are bile acids with neuroprotective and homeostatic properties due to their capacity to inhibit glutamate release [5]. Based on these findings, a possible hypothesis is presented, stating that UDCA may be effective in reducing the psychotic and cognitive symptoms among patients with schizophrenia. In line with the above hypothesis, our report presented a 12week treatment course for a patient with TRS who made significant improvement in positive, negative, and cognitive symptoms following initiation of UDCA.

(c) The Author(s). 2020 Open Access This article is licensed under a Creative Commons Attribution 4.0 International License, which permits use, sharing, adaptation, distribution and reproduction in any medium or format, as long as you give appropriate credit to the original author(s) and the source, provide a link to the Creative Commons licence, and indicate if changes were made. The images or other third party material in this article are included in the article's Creative Commons licence, unless indicated otherwise in a credit line to the material. If material is not included in the article's Creative Commons licence and your intended use is not permitted by statutory regulation or exceeds the permitted use, you will need to obtain permission directly from the copyright holder. To view a copy of this licence, visit http://creativecommons.org/licenses/by/4.0/ The Creative Commons Public Domain Dedication waiver (http://creativecommons.org/publicdomain/zero/1.0/) applies to the data made available in this article, unless otherwise stated in a credit line to the data. 


\section{Case presentation}

A 39-year-old Persian man, without any positive family history, was referred to our hospital with a 15-year history of command hallucination, persecutory delusion, social isolation, hostility/excitement, anxiety, depression, and cognitive impairment, which had been treated at a psychiatric clinic with the diagnosis of schizophrenia. Although he had already been admitted to a psychiatric hospital six times during 15 years, his records indicated the progressive course of the disease and his failure to respond to various treatment regimens. No abnormal findings were observed in a physical examination, imaging, and laboratory tests. Finally, he was treated with clozapine with a diagnosis of TRS, which was eventually terminated due to its adverse effects, including restlessness, tachycardia, tremor, sialorrhea, nausea, and disturbed sleep. After discontinuation of clozapine, although he was treated with olanzapine, carbamazepine, fluvoxamine, lorazepam, propranolol, and fluphenazine decanoate injection for 2 years, no significant improvement was made. At the end of the second year of treatment with the above medication regimen, mirtazapine of $15 \mathrm{mg} /$ day was added to the previous regimen and increased to $30 \mathrm{mg} /$ day due to exacerbation of anorexia, insomnia, and anxiety. Despite a relative improvement in anorexia, anxiety, and insomnia, a laboratory test revealed an elevated alanine transaminase (ALT) level compared to the previous test ( $147 \mathrm{U} / \mathrm{L}$ versus $22 \mathrm{U} / \mathrm{L}$; reference range, up to $41 \mathrm{U} / \mathrm{L}$ ). Given an internal medicine consultation, mirtazapine was discontinued after 2 months, and he started taking UDCA $300 \mathrm{mg}$ capsules twice a day. In the fourth week of treatment, his ALT level was reduced ( $28 \mathrm{U} / \mathrm{L}$; reference range, up to $41 \mathrm{U} /$ L). Also, his positive, negative, and cognitive symptoms significantly decreased during the eighth week of followup and continued with a mild slope throughout the tenth and 12th weeks of the treatment. There was a significant difference between the mean scores of the Positive and Negative Syndrome Scale (PANSS) and the Mini-Mental State Examination (MMSE) before and 12 weeks after the treatment with UDCA (149 versus 65 and 13 versus 26, respectively). Also, UDCA was well tolerated, and our patient did not exhibit any side effects during treatment based on interview and physical examination. Figure 1 presents the 12-week follow-up of our patient according to PANSS and MMSE.

\section{Discussion and conclusions}

Although the dopamine hypothesis of schizophrenia has been raised, poor response to antipsychotics may indicate that some patients with TRS have suffered from non-dopamine pathophysiology [6]. In this respect, a theory that was first proposed in the 1980s, and gained further support in the following years, attributed the biological origin of schizophrenia symptoms to the glutamate neurotransmitter, rather than dopamine [7]. This theory states that NMDAR dysfunction in schizophrenia leads to excessive glutamate release of cortico-pyramidal neurons, which can produce the full range of schizophrenia symptoms and cognitive impairments [6].

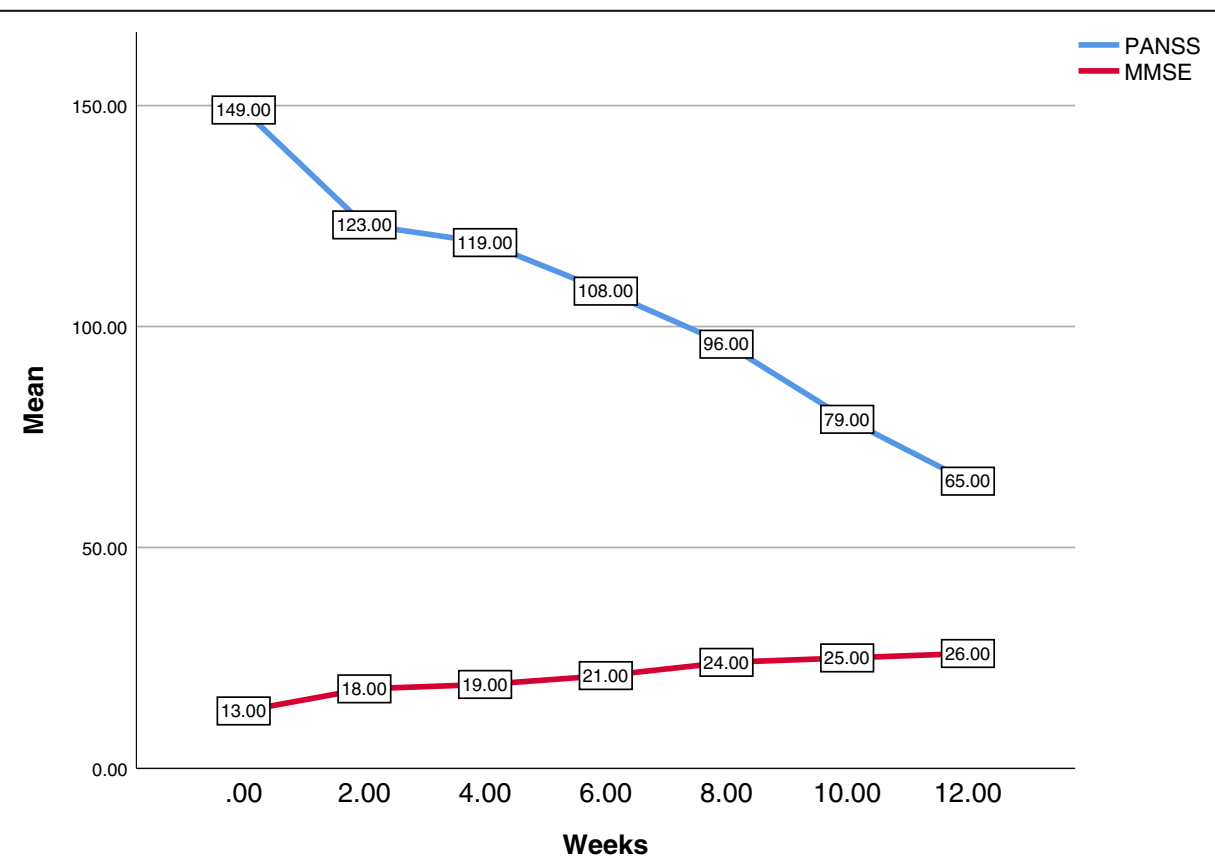

Fig. 1 Multiple-line mean of Mini-Mental State Examination and Positive and Negative Syndrome Scale over weeks. MMSE Mini-Mental State Examination, PANSS Positive and Negative Syndrome Scale 
Consistent with this theory, new research over the past decade has suggested that bile acids may reduce the production of glutamate [5]. For instance, Silva et al. [5] claimed that the overstimulation of glutamate receptors to induce excitotoxicity in neurons isolated from latestage fetal rat brains was largely suppressed by GUDCA. As a result, the bile acid seems to inhibit glutamate release in either normal or microglia-depleted hippocampal tissue slices.

Our results demonstrated that UDCA augmentation might be an effective treatment strategy for patients with TRS. According to the glutamate hypothesis of schizophrenia models, some of the possible therapeutic mechanisms are: (a) A reduced tone of glutaminergic projection neurons - which under-stimulates GABAergic interneurons in the ventral tegmental area- might lead the mesocortical dopamine pathway to be activated. This procedure results in sufficient dopamine release in the prefrontal cortex (PFC) and, in turn, decreases the cognitive and negative symptoms [8]; (b) the reduced firing of cortical glutaminergic projection neurons could cause dopamine mesolimbic pathway hypoactivation, which diminishes the positive symptoms $[8,9]$.

Moreover, retinoic acid as a neurotrophic factor shares a common role in regulating lipid homeostasis with bile acids via activating the farnesoid $\mathrm{X}$ receptor (FXR) signaling pathway or vice versa. Accordingly, bile acids are likely to exert mediating effects on the nervous system through a similar mechanism that is not completely known $[4,10]$.

Although the clinical consumption of UDCA has been acceptably safe, the UDCA efficacy for TRS is still debated. The molecular functions of bile acids have been widely discovered; however, the mechanism of UDCA needs to be further explored. Further studies on bile acids may be beneficial for developing more efficient approaches to using this classical compound as a new drug in TRS.

\section{Abbreviations}

ALT: Alanine transaminase; FXR: Farnesoid X receptor; GUDCA: Glycoursodeoxycholic acid; MMSE: Mini-Mental State Examination; NMDAR: N-methyl-D-aspartate receptor; PANSS: Positive and Negative Syndrome Scale; PFC: Prefrontal cortex; TRS: Treatment-refractory schizophrenia; UDCA: Ursodeoxycholic acid

\section{Acknowledgements}

The author would like to thank the patient, who contributed in conducting the present study.

\section{Author's contributions}

MKH conceptualized the commentary/report, edited the manuscript, and prepared the figure. MKH also approved of the final version of the submitted manuscript.

\section{Funding}

The author received no specific funding for this work.
Availability of data and materials

The patient's information and medical records used for the case report are available from the corresponding author upon request.

Ethics approval and consent to participate

All procedures were according to the latest version of the Declaration of Helsinki. Prior to participation, written informed consent was obtained from the patient and his parents/legal guardians after a comprehensive explanation of the study procedures.

\section{Consent for publication}

Written informed consent was obtained from the patient for publication of this case report and any accompanying images. A copy of the written consent is available for review by the Editor-in-Chief of this journal.

\section{Competing interests}

The author declares that he has no competing interests.

Received: 6 April 2020 Accepted: 5 August 2020

Published online: 01 September 2020

References

1. Ajnakina O, Horsdal HT, Lally J, MacCabe JH, Murray RM, Gasse C, et al. Validation of an algorithm-based definition of treatment resistance in patients with schizophrenia. Schizophr Res. 2018;197:294-7.

2. Siskind D, McCartney L, Goldschlager R, Kisely S. Clozapine v. first-and second-generation antipsychotics in treatment-refractory schizophrenia: systematic review and meta-analysis. Br J Psychiatry. 2016;209(5):385-92.

3. Lin $\mathrm{CH}$, Chen YM, Lane HY. Novel Treatment for the Most Resistant Schizophrenia: Dual Activation of NMDA Receptor and Antioxidant. Curr Drug Targets. 2020;21(6):610-5.

4. Ackerman HD, Gerhard GS. Bile acids in neurodegenerative disorders. Front Aging Neurosci. 2016;8:263

5. Silva SL, Vaz AR, Diógenes MJ, van Rooijen N, Sebastião AM, Fernandes A, et al. Neuritic growth impairment and cell death by unconjugated bilirubin is mediated by NO and glutamate, modulated by microglia, and prevented by glycoursodeoxycholic acid and interleukin-10. Neuropharmacology. 2012; 62(7):2398-408

6. Laruelle M. Schizophrenia: from dopaminergic to glutamatergic interventions. Curr Opin Pharmacol. 2014;14:97-102.

7. Balu DT. The NMDA Receptor and Schizophrenia: From Pathophysiology to Treatment. Adv Pharmacol. 2016;76:351-82.

8. Ellaithy A, Younkin J, Gonzalez-Maeso J, Logothetis DE. Positive allosteric modulators of metabotropic glutamate 2 receptors in schizophrenia treatment. Trends Neurosci. 2015;38(8):506-16.

9. Lisman JE, Coyle JT, Green RW, Javitt DC, Benes FM, Heckers S, Grace AA. Circuit-based framework for understanding neurotransmitter and risk gene interactions in schizophrenia. Trends Neurosci. 2008:31(5):234-42.

10. Yang F, He Y, Liu HX, Tsuei J, Jiang X, Yang L, et al. All-trans retinoic acid regulates hepatic bile acid homeostasis. Biochem Pharmacol. 2014; 91(4):483-9.

\section{Publisher's Note}

Springer Nature remains neutral with regard to jurisdictional claims in published maps and institutional affiliations.

Ready to submit your research? Choose BMC and benefit from:

- fast, convenient online submission

- thorough peer review by experienced researchers in your field

- rapid publication on acceptance

- support for research data, including large and complex data types

- gold Open Access which fosters wider collaboration and increased citations

- maximum visibility for your research: over $100 \mathrm{M}$ website views per year

At $\mathrm{BMC}$, research is always in progress.

Learn more biomedcentral.com/submissions 